\title{
ВИЗНАЧЕННЯ ЕНЕРГОСИЛОВИХ ПАРАМЕТРІВ ПРОЦЕСУ ВИДАВЛЮВАННЯ ЦИЛІНДРИЧНИХ ДЕТАЛЕЙ 3 КВАДРАТНИХ ЗАГОТОВОК
}

Процеси холодного об'ємного штампування і видавлювання відрізняються високою ефективністю і продуктивністю завдяки можливості максимального наближення параметрів заготовок до вимог готової деталі [1-3]. Як правило, заготовки для формоутворюючих операцій холодного видавлювання з відносною висотою $h=(0,1 \ldots 0,2) \cdot D$ отримують вирубкою 3 листа, штаби або стрічки. Якщо заготовки мають квадратну або шестигранну форму, то використовують розкрій без перемичок. При цьому для квадратних заготовок коефіцієнт використання матеріалу наближається до 100 \%. Якщо ж заготовки мають круглу форму, то навіть при багаторядному розкрої коефіцієнт використання матеріалу не перевищує 72 \%. Таке неекономне витрачання металу не можна визнати доцільним, особливо при штампуванні кольорових металів та їх сплавів.

Спроби отримання низьких (коротких) заготовок різкою зсувом круглого прокату в спеціальних штампах позитивного результату не мали $[4,5]$. Відомі способи торцевого розкочування заготовок [6-10] характеризуються недостатньо високою продуктивністю і можуть призводити до формування дефектів.

Метою даної роботі є дослідження більш ефективного способу виготовлення подібних заготовок, який містить осадку квадратної заготовки в циліндричній матриці і одночасне видавлювання порожнистої деталі типу стакан.

Схему осадження квадратної заготовки в циліндричній матриці представлено на рис. 1. При протіканні цього процесу виникає вихрова течія металу, аналіз якої можливий тільки на базі математичного моделювання невісесиметричних процесів. Задачі, в яких має місце тривимірна невісесиметрична течія, з достатньою точністю можуть бути вирішені енергетичним методом в циліндричній системі координат в його класичному варіаційному вигляді. Поділ заготовки на області базується на результатах, які були отримані в ході попередніх експериментів. Експериментально встановлено, як саме відбувається заповнення металом матриці і які відповідні функції, що описують поле швидкостей течії металу, можна використовувати. У зв'язку з симетрією деталі можна розглядати тільки $1 / 8$ іï частину (рис. 2). Для зручності розрахунків на рис. 2 заготовку повернуто на кут $\pi / 4$ проти годинникової стрілки.

Осередок деформації розбиваємо на дві області: 1 - область тривимірної течії металу, 2 - область вихрової течії. Очевидно, що в процесі осадки кут заповнення $\theta_{3}$, який визначає область 2, збільшується, а кут $\alpha$, який визначає область 1 , зменшується. При цьому хорда $A B$ стягується, зазор між стороною заготовки і стінкою матриці зменшується від $S_{0}$ (див. рис. 1 ) до $s$ (див. рис. 2).

Маємо наступні очевидні співвідношення:

$$
d_{\mathrm{M}}=2 \cdot r_{\mathcal{M}}=A_{0} \cdot \sqrt{2} ; \quad b_{1}=r_{M} \cdot \sin \alpha ; \quad k_{1}=r_{M} \cdot \cos \alpha ; \quad \alpha=\frac{\pi}{4}-\theta_{3},
$$

де $d_{M}$ - діаметр матриці; $r_{M}$ - радіус матриці; $A_{0}$ - розмір сторони заготовки; $h_{0}$ - початкова висота заготовки; $h$ - висота заготовки в процесі деформації; $k_{1}$ i $b_{1}-$ катети трикутної області 1.

Незаповнення контуру матриці $s$ визначається за формулою $s=r_{M} \cdot(1-\cos \alpha)$.

Компоненти швидкостей деформації $v_{r}, v_{\theta}, v_{z}$, що входять в основне рівняння енергетичного методу, представляємо у вигляді так званих відповідних функцій, дотримуючись граничних умов і умови сталості обсягу. Аналіз опублікованих даних і числові розрахунки 
показують, що вид відповідних функцій швидкостей незначно впливає на зусилля деформування [11]. Це дозволяє при аналізі процесів зі складною кінематикою течії металу використовувати порівняно прості розривні функції, отримуючи при цьому рішення 3 достатньою для практики точністю.

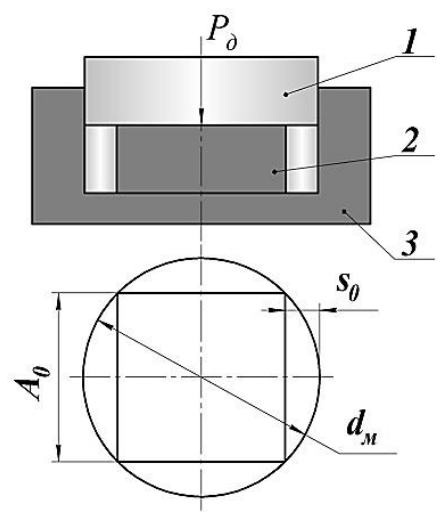

Рис. 1. Схема осадки:

1 - пуансон; 2 - заготовка;

3 - матриця

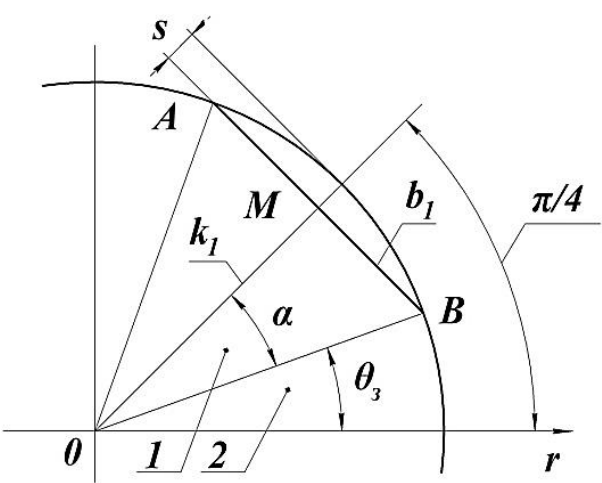

Рис. 2. Розбивка заготовки на області

Умова сталості об’єму для тривимірної задачі в циліндричній системі координат має вигляд:

$$
\frac{\partial v_{r}}{\partial r}+\frac{\partial v_{Z}}{\partial z}+\frac{1}{r} \cdot\left(\frac{\partial v_{\theta}}{\partial \theta}+v_{r}\right)=0
$$

Беручи до уваги граничні умови в областях 1 і 2 (див. рис. 2), у прийнятій розрахунковій схемі течія металу може бути описана наступними залежностями:

в області 1: по осі $z-$ при $z=0 \quad v_{z}=0$; при $z=h \quad v_{z}=-v_{\Pi}$;

$$
\text { по осі } r \text { - при } r=0 \quad v_{r}=0 \text {. }
$$

в області 2: по осі $z-$ при $z=0 \quad v_{z}=0$; при $z=h \quad v_{z}=-v_{\Pi}$;

$$
\text { по осі } r \text { - при } 0 \leq r \leq r_{M} \text { i } \theta<\theta_{3} \quad v_{r}=0, v_{\theta} \neq 0 \text {. }
$$

Оскільки області 1 і 2 мають однакові граничні умови по $z$, то компонента $v_{z}$ для них однакова. Приймаємо іiі у вигляді лінійної функції від z. 3 урахуванням граничних умов знаходимо $v_{z 1,2}=-\frac{v_{\Pi}}{h_{0}} z$.

Області 1 і 2, на які поділено заготовку, за граничними умовами істотно відрізняються одна від одної. Тому розглянемо їх окремо.

Для визначення $v_{r 1}$ скористаємося умовою сталості об’єму (1). Після інтегрування отримуємо:

$$
v_{r 1}=\frac{-1}{r} \cdot\left[\int \frac{\partial v_{\theta}}{\partial \theta} d r+\left(\frac{-v_{\Pi}}{h}\right) \cdot \frac{r^{2}}{2}+C_{1}\right] .
$$

Для визначення $v_{r 1}$ введемо спрощення - представимо $v_{\theta 1}$ у вигляді лінійної функції:

$$
v_{\theta 1}(\theta)=m \theta+b
$$


Враховуючи граничні умови (при $\theta=\frac{\pi}{4} v_{\theta}=0$; при $\theta=\theta_{3}=\frac{\pi}{4}-\alpha \quad v_{\theta 1}=v_{\theta 2}$ ), знаходимо $v_{\theta 1}=\frac{v_{\Pi \Pi} \cdot r}{h} \cdot\left(\frac{\pi}{4}-\theta\right) \cdot\left(\frac{\pi}{4 \cdot \alpha}-1\right)$.

Використовуючи співвідношення (1), знаходимо $v_{r 1}=\frac{v_{\Pi} \cdot r \cdot \pi}{8 \cdot h \cdot \alpha}$.

Оскільки метал в зоні 2 не тече в радіальному напрямку, то приймаємо $v_{r 2}=0$. Компоненту $v_{\theta 2}$ визначаємо 3 умови сталості об'єму, скориставшись граничними умовами $v_{\theta}=0$ при $r=0$, тоді $v_{\theta 2}=\frac{v_{\Pi} \cdot r}{h} \cdot \theta$.

Кут $\alpha$ визначаємо з умови рівності об’єму вихідної і деформованої заготовки:

$$
\frac{1}{8} \cdot A_{0}^{2} \cdot h_{0}=\left(S_{C}+S_{m}\right) \cdot h
$$

де $S_{c}$ - площа сектора (область 2, рис. 2); $S_{m}$ - площа трикутника (область 1 , рис. 2 ).

Площі сектора (зона 2) і трикутника (зона 1) визначаємо за формулами:

$$
S_{c}=\frac{\pi \cdot r_{m}{ }^{2} \cdot\left(\frac{\pi}{4}-\alpha\right)}{360} ; \quad S_{m}=\frac{1}{2} \cdot k_{1} \cdot b_{1}=\frac{1}{4} \cdot r_{m}{ }^{2} \cdot \sin 2 \alpha \text {. }
$$

Тоді умову сталості об’єму в ході процесу видавлювання деталі можна записати в наступному вигляді:

$$
\frac{\frac{1}{8} \cdot A_{0}^{2} \cdot h_{0}}{r_{\mathcal{M}}^{2} \cdot\left(h_{0}-\Delta h\right)}-\frac{\sin 2 \alpha}{4}-0,5 \cdot\left(\frac{\pi}{4}-\alpha\right)=0
$$

і отримати значення $\alpha$ - кута трикутника області 1 , який зменшується в ході деформації в міру розширення області 2 (заповнення порожнини матриці і зменшення зазору s).

Визначаємо компоненти швидкостей, а потім інтенсивність деформації для кожної з областей. Аналіз процесу виконано за допомогою числових методів інтегрування [12]. Це дозволяє проаналізувати поле швидкостей і створену математичну модель процесу. Отримані залежності для компонент швидкостей, швидкостей деформації та інтенсивності швидкостей деформації дають можливість описати деформований стан у всьому об'ємі заготовки і перейти до побудови математичної моделі процесу. Для цього використовуємо перше основне рівняння енергетичного методу [11], яке виражає умову рівності потужностей всіх внутрішніх і зовнішніх сил. 3 якого знаходимо відносне питоме зусилля деформації $\bar{p}$ :

$$
\bar{p}=\frac{1}{v_{\Pi} \cdot \sigma_{S} \cdot A} \cdot \sum_{i=1}^{n} N_{i}
$$

Тут $N_{i}$ - потужності внутрішніх сил опору деформації, контактного тертя і зсуву, обчислені для кожної із зон деталі; $v_{\Pi}-$ швидкість пуансона; $\sigma_{s}-$ напруження плину заготовки, що деформується; $A$ - площа заготовки.

Співвідношення (2) $є$ функція властивостей деформованого матеріалу $\left(\sigma_{s}\right)$, розмірів заготовки $\left(A_{0}\right)$ і інструменту $\left(r_{m}\right)$, умов тертя на контактних поверхнях матриці і пуансона $\left(\mu_{1}\right.$ i $\left.\mu_{2}\right)$. Це співвідношення $\epsilon$ неявна функція кута $\alpha$, яку можна розглядати як математичну модель процесу осадки квадратної заготовки в циліндричної матриці. Ця функція не має ана- 
літичного рішення щодо $\alpha$, тому вирішуємо його за допомогою одного з відомих числових методів рішення рівнянь [12]. Рішення представляємо в графічному вигляді (рис. 3).

Теоретичне рішення перевіряли експериментально. Осадку квадратних заготовок проводили в циліндричної матриці на пресі УВМ-50М. На заготовку для визначення течії металу наносили ортогональні і радіальні координатні сітки. Деформували одночасно дві заготовки, між якими розташовували тонкий папір. За спотворенням сітки і характерним рельєфом на папері виявляли особливості течії металу.
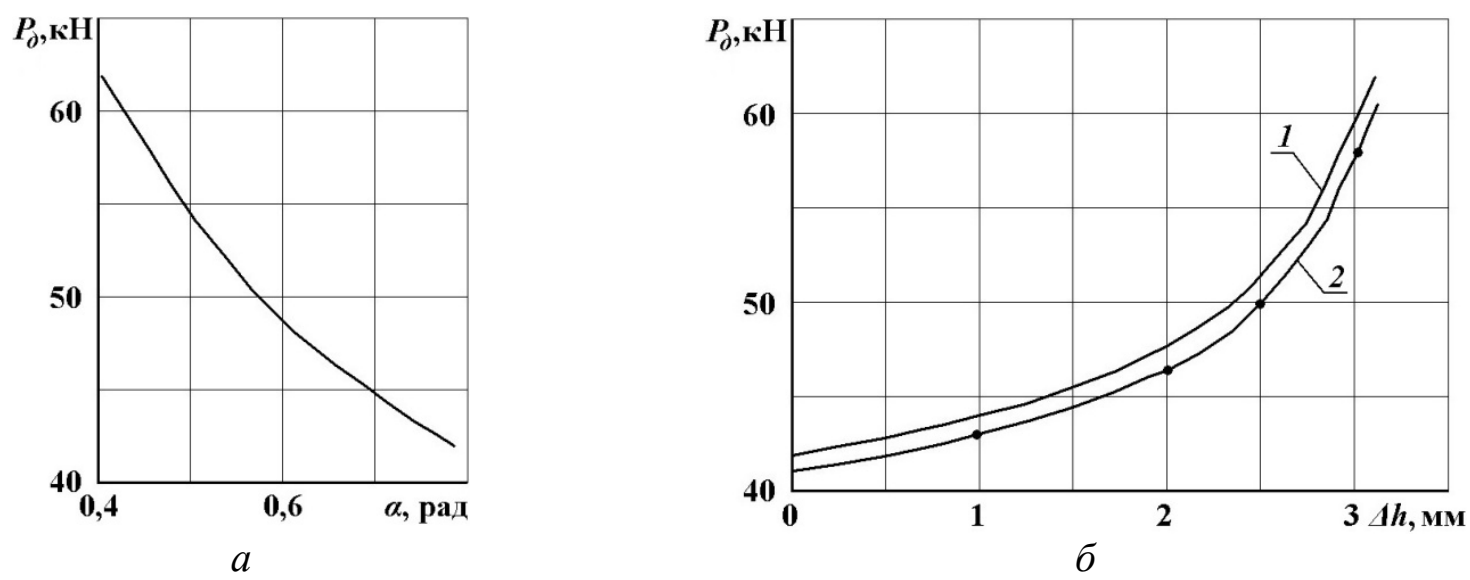

Рис. 3. Залежність зусилля осадки квадратної заготовки в циліндричної матриці:

$a$ - від кута незаповнення $\alpha$; $\sigma$ - від ходу пуансона $\Delta h(1-$ розрахункова крива, 2 - експериментальна крива; • - експериментальні точки)

Експерименти на свинцевих заготовках показали хорошу збіжність теоретичних та експериментальних даних. Тому теоретичний підхід використовували для розробки нової технології видавлювання тонкостінних циліндричних деталей типу стаканів (тюбиків).

Для виготовлення циліндричної деталі методом видавлювання традиційно застосовують круглі заготовки. Як зазначалося вище, при вирубуванні заготовки круглої форми коефіцієнт використання матеріалу невисокий. Тому застосування технології отримання круглих деталей з квадратних заготовок є вельми перспективним. Це має особливо велике значення при використанні кольорових металів. При виготовленні круглої заготовки 3 квадратної в якості матеріалу використовують лист. При цьому коефіцієнт використання матеріалу підвищується до 0,98 .

Теоретичною основою нового технологічного процесу можуть бути графіки, на яких поєднано залежності питомих сил від незаповнення $s$ для осадки квадратної заготовки, а також для стаціонарної стадії видавлювання заготовок типу стаканів 3 товщиною стінки $t=0,50$ мм і $t=0,25$ мм (рис. 4).

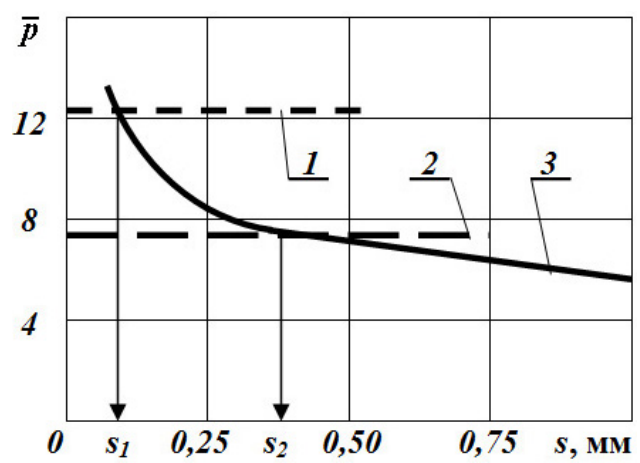

Рис. 4. Графіки залежностей питомих сил від незаповнення $s$ :

1 - видавлювання стакана 3 товщиною стінки $t_{1}=0,25$ мм; 2 - видавлювання стакана 3 товщиною стінки $t_{2}=0,50$ мм; 3 - осадка квадратної заготовки 
3 рис. 4 видно, що при зменшенні незаповнення $s$ графік залежності відносного питомої сили деформації $\bar{p}$ асимптотично наближається до осі ординат. Це свідчить про те, що для отримання ідеально круглої деталі з квадратної заготовки потрібно нескінченно велика сила. Однак в тому випадку, коли осадку поєднано з видавлюванням стакану, останній процес може початися раніше, ніж незаповнення стане рівним товщині стінки стакану. При цьому можливі два випадки. Якщо стакан особливо тонкостінний $(t=0,25)$, то для його видавлювання потрібна сила, більша, ніж сила, необхідна для осадки заготовки за умови, що $s_{1}=t$. Тому при силі, яка необхідна для видавлювання стакану, незаповнення $s_{1}$ буде меншим, ніж товщина стінки. Якщо стакан матиме більш товсту стінку $(t=0,50)$, то для його видавлювання потрібна сила, менша, ніж сила, необхідна для осадки заготовки за умови, що $s_{2}=t$. Тому при силі, яка необхідна для видавлювання стакану, незаповнення $s_{2}$ буде більшим, ніж товщина стінки. Однак в обох випадках течія металу в стінку буде нерівномірною за кутом $\theta$, в зв'язку з чим на верхньому торці стінки отримаємо фестон. У першому випадку він буде меншим, ніж у другому. При видавлюванні деталей типу тонкостінних стаканів завжди передбачається припуск на обрізку торця. Тому фестони не є перешкодою для виготовлення тонкостінних деталей типу тюбиків. Запропонована методика теоретичного аналізу може бути використана для визначення товщини стінки, при якій фестон не буде перешкодою для виготовлення тонкостінних деталей. Запропоновано технологічний процес виготовлення тюбиків для косметичної промисловості з квадратних заготовок. За трудомісткістю новий процес практично не відрізняється від традиційного, а за коефіцієнтом використання матеріалу $\eta-$ значно його перевершує (табл. 1).

Таблиця 1

Порівняння технологій виготовлення тюбиків

\begin{tabular}{|l|l|}
\hline \multicolumn{1}{|c|}{ Традиційна технологія $(\eta=0,67)$} & \multicolumn{1}{c|}{ Нова технологія $(\eta=0,98)$} \\
\hline 1. Різка листа на штаби & 1. Різка листа на штаби \\
2. Вирубка круглих заготовок & 2. Відрізка квадратних заготовок в штампі \\
3. Змащування в галтувальному барабані & 3. Змащування в галтувальному барабані \\
4. Видавлювання тюбиків & 4. Видавлювання тюбиків \\
\hline
\end{tabular}

\section{ВИСНОВКИ}

Теоретичний аналіз і експериментальне дослідження показали, що процес осадки квадратної заготовки в циліндричній матриці протікає за схемою вихрової течії.

Математичну модель даного процесу можна побудувати тільки з використанням тривимірного вихрового поля швидкостей на базі енергетичного методу.

Розглянуто використання тривимірного вихрового поля для конкретного процесу видавлювання тюбиків з квадратних заготовок.

Застосування нової технології видавлювання тюбиків з квадратних заготовок дозволяє за тієї ж трудомісткості виготовлення деталей підвищити коефіцієнт використання матеріалу з 0,67 до 0,98 .

\section{СПИСОК ВИКОРИСТАНОЇ ЛІТЕРАТУРИ}

1. Соколов Л. Н., Ефимов В. Н., Алиев И. С., Кащенко Ю. А. Кузнецу-штамповщику. Справочное пособие. Донецк: Донбас, 1986. 144 с.

2. Алієв I. С. Методи пошуку нових технологічних способів видавлювання. Теорія та практика обробки матеріалів тиском : колективна монографія / під ред. Богуслаєва В. О., Бобиря М. І., Тітова В. А., Качана О. Я. Запоріжжя: АТ «Мотор Січ», 2016. С. 364-385.

3. Алиева Л. И. Совершенствование процессов комбинированного выдавливания: монография. Краматорск: ООО «Тираж - 51», 2018. 352 с.

$176 \mathrm{c}$.

4. Соловцов С. С. Безотходная резка сортового проката в штампах. Москва: Машиностроение, 1985.

5. Алифанов А. В., Захаревич Л. В., Макушок Е. М., Оленин Л. Д. Технологические процессы пластического деформирования в машиностроении. Минск: Наука и Техника, 1989. 208 с. 
6. Авдеев В. М., Аксенов Л. Б., Алиев И. С. и др. Изготовление заготовок и деталей пластическим деформированием; под ред. К. Н. Богоявленского, В. В. Риса. Ленинград: Политехника, 1991. 351 с.

7. Алієв І. С., Матвийчук В. А. Развитие локальных методов обработки металлов давлением. Обработка материалов давлением. Краматорск: ДГМА, 2008. 1(19). С. 201-204.

8. Матвійчук В. А., Михалевич В. М., Краєвський В. О. Розробка маловідходних процесів формування тонкостінних циліндричних деталей. Удосконалення процесів і обладнання обробки тиском в металургії $i$ машинобудуванні. Краматорськ: ДДМА, 2004. С. 281-286.

9. Краєвський В. О., Матвійчук В. А., Михалевич В. М. Вплив технологічних параметрів на кінематику холодного торцевого розкочування. Удосконалення процесів і обладнання обробки тиском в металургї̈ і машинобудуванні. Краматорськ-Слов'янськ: ДДМА, 2003. С. 286-291.

10. Матвийчук В. А., Алиев И. С. Совершенствование процессов локальной ротационной обработки давлением на основе анализа деформируемости металлов: монография. Краматорск: ДГМА, 2009. 268 с.

11. Евстратов В. А. Теория обработки металлов давлением. Харьков: Выща школа, 1981. 248 с.

12. Левченко В. М., Алієва Л. І., Малій Х. В. Методи обчислювальної математики в обробці металів тиском: посібник для студентів галузі знань 13 «Механічна інженерія» денної та заочної форм навчання. Електрон. дані. Краматорськ: ДДМА, 2020. 1 електрон. опт. диск (CD-ROM); 12 см.

\section{REFERENCES}

1. Sokolov L.N., Efimov V.N., Aliev I.S., Kashchenko Yu.A. et al. To the blacksmith-stamper. Reference manual. Donetsk: Donbas. 1986. 144 p. (in Russian).

2. Aliiev I.S. Methods of searching for new technological methods of extrusion. Theory and practice of material processing by pressure: a collective monograph. Eds. Boguslaev V.O., Bobir M.I., Titov V.A., Kachan O.Ya. Zaporizhia: Motor Sich JSC. 2016, pp. 364-385. (in Ukrainian).

3. Aliieva L.I. Improvement of combined extrusion processes: monograph. Kramatorsk: LLC "Tiraj - 51". 2018. 352 p. ISBN 978-966-379-846-2. (in Russian). (in Russian).

4. Solovtsov S.S. Waste-free cutting of long products in dies. Moscow: Mechanical Engineering. 1985. 176 p.

5. Alifanov A.V., Zaharevich L.V., Makushok E.M., Olenin L.D. Technological processes of plastic deformation in machine building. Minsk: Science and Technology. 1989. 208 p. (in Russian).

6. Avdeev V.M., Aksenov L.B., Aliiev I.S. et al. Manufacturing of blanks and parts by plastic deformation. Eds. K.N. Bogoyavlenskiy, V.V. Ris. Leningrad: Polytechnic. 1991. 351 p. (in Russian).

7. Aliiev I. S., Matviychuk V.A. Development of local methods of metal working by pressure. Materials Working by Pressure. Kramatorsk: DSEA. 2008. 1 (19), pp. 201-204. (in Russian).

8. Matvijchuk V.A., Myhalevych V.M., Krayevskyj V.O. Development of low-waste processes of forming of thin-walled cylindrical parts. Improvement of Processes and Equipment for Pressure Working in Metallurgy and Machine Building. Kramatorsk: DSEA. 2004, pp. 281-286. (in Ukrainian).

9. Krayevskyj V.O., Matvijchuk V.A., Myhalevych V.M. Influence of technological parameters on the kinematics of cold end rolling out. Improvement of Processes and Equipment for Pressure Working in Metallurgy and Machine Building. Kramatorsk-Slovyansk: DSEA. 2003, pp. 286-291. (in Ukrainian).

10. Matviychuk V.A., Aliiev I.S. Improving the processes of local rotational pressure working based on the analysis of the deformability of metals: Monograph. Kramatorsk: DSEA. 2009. 268 p. (in Russian).

11. Evstratov V.A. Theory of metal working by pressure. Kharkov: Higher school. 1981. 248 p. (in Russian).

12. Levchenko V.M., Aliieva L.I., Malii Kh.V. Methods of computational mathematics in the metal working by pressure: the guide for students in the field of knowledge 13 "Mechanical Engineering". Electron. data. Kramatorsk: DSEA. 2020. 1 electron. opt. disk (CD-ROM); $12 \mathrm{~cm}$. (in Ukrainian).

Кротенко Г. А. - канд. техн. наук, доц. НТУ «ХПІ»;

Левченко В. М. - канд. техн. наук, ст. наук. співроб., докторант ДДМА;

Таган Л. В. - канд. техн. наук, ст. викл. ДДМА.

НТУ «ХПІ»-Національний технічний університет «Харківський політехнічний інститут», м. Харків.

ДДМА - Донбаська державна машинобудівна академія, м. Краматорськ.

E-mail: goldangel271@gmail.com 